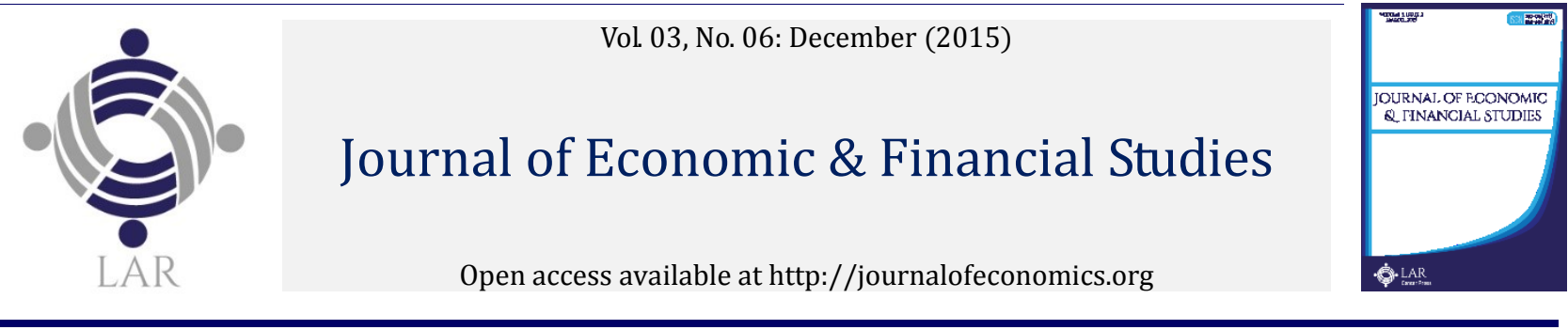

\title{
Effects of regional development policies on the resolution of income disparity in China
}

\author{
Hong-Yul Jeong a Jong-Hag Jang $\mathrm{b}^{*}$, \\ a Professor, College of International Studies, Korea Maritime and Ocean University, Korea. Email: jhy@hhu.ac.kr \\ ${ }^{\mathrm{b}}$ Professor, School of Economics and Management, Chang'an University, China. \\ ${ }^{*}$ Corresponding author's email address: 1225317060@qq.com
}

\begin{abstract}
AR T I C L E I N F O
Received: 16-12-2015

Accepted: 06-01-2016

Available online: 08-01-2016

Keywords:

Coefficient of variation analysis,

Gini coefficient analysis,

Income disparity,

Regional development policy,

Theil index analysis.

JEL Classification:

E25, E61, R11, R58.

A B S T R A C T

Using thirty provincial panel-data from 1949 to 2010 that is separated into four periods, this paper examines the details of major regional development policies in practice by China so far since its foundation, and focuses on the analysis of how those policies influenced the resolution of inequality between regions through Gini coefficient analysis, coefficient of variation analysis and Theil index analysis. The results of income inequality analysis in Mao's time show that income inequality coefficients are ups and downs. In the age of the reform and open-door policy, the income disparity in the eastern region drastically decreased, which in turn reduced the national income disparity among regions. However, from the 1990s the income convergences among regions in eastern coastal areas began to cease, which resulted in spreading income disparity among the regions all over China. Even though coefficients of income inequality indices have decreased since the mid-2000s, it may take more observation to decide whether such phenomenon is the result of the policy of 'building of a harmonious society' pursued by Hu Jintao.
\end{abstract}

(C) 2016 The Authors. This is an open access article under the terms of the Creative Commons Attribution License 4.0, which allows use, distribution and reproduction in any medium, provided the original work is properly cited.

DOI: http://dx.doi.org/10.18533/jefs.v3i6.204

\subsection{Introduction}

China has various favorable conditions for economic growth, such as a huge consumption market, strong government, abundant labor force, etc. However, until 1978, China had 2.3\% of annual economic growth per capita in real GDP under the government's equality and economic self-reliance development strategy, which was far behind not only Japan or other emerging industrial countries in Asia but also some Southeast Asian countries and the communist country the Soviet Union.

Then, for 30 years, since 1978 when Den Xiaoping's reform and open-door policy gained success, the country has shown unprecedented annual economic growth at $9 \%$ of the world, emerging as one of the economic powers. Consequently, China's GDP of 138.8 billion dollars in 1978 increased to 5.9 trillion dollars in 2010, following the United States by ranking second and leaving Japan and Germany behind. With the fast-growing economic growth, the levels of per capita income has greatly improved from \$154 in 1978 to \$4,412 in 2010, entering the medium-sized economies in terms of per capita income for the first time in 30 years after the reform and open-door policy. This rapid economic growth, however, has tended to be concentrated on certain regions rather than all across the country, which has widened economic disparity among regions, urban and countryside, and among social classes, and is bringing about new social concern and political tension in China. 
Many scholars and experts have studied the issue of regional disparity. Until recently, however, there were insufficient resources suited for estimating the imbalance of income between regions resulting in the researchers collecting, processing, and using data on their own such as gross value of industrial, agricultural outputs, net material product, and national income utilized and so on. Consequently, there are a number of examples of different income inequality figures predictions that use the same inequality index with identical regions during the same period, and these confused many researchers.

To resolve the issue of data inconsistency and lack of clarity posed by previous studies, this study uses the statistics book "Compendium of Statistics 1949-2004" published by the Chinese government in 2005. This book provides clear, detailed information regarding GDP of each region from 1949 to 2004 . The data after 2004 is taken from "China Statistical yearbook".

This study examines the details of China's major regional development policies since its foundation, and focuses on the analysis of how these policies influenced the resolution of inequality between regions through Gini coefficient analysis, coefficient of variation analysis and Theil index analysis.

The results of the income inequality analysis of Mao's time show that income inequality coefficients are up and down. In the age of the reform and opendoor policy, the income disparity in the eastern region drastically decreased, which in turn reduced the national income disparity among regions. However, from the 1990s the income convergences among regions in eastern coastal areas began to cease, which resulted in spreading income disparity among the regions all over China. The coefficients of income inequality indices have decreased since the mid-2000s.

Equilibrium regional growth is a plan to create a balanced society so that all regions share balanced prosperity and to fulfill national integration, and the development of the central and western regions of China should be achieved for China to become the 21st century great economic power. In order to attain this goal, the government needs to support underdeveloped regions in the eastern region while it conducts a preferential development plan for the central and western regions of China.

This paper is organized in the following manner. Section 2 examines prior studies on regional income disparity in China. Section 3 includes the estimated income disparity among the regions in China and consideration of the issues found from the conducted. Section 4 and 5 contains the elaboration of indices utilized for income disparity estimation and analysis of the estimated result. In conclusion, section 6 explains the general characteristics of the trend of regional income disparity in China and suggests policy implications to control the income inequality in this country.

\section{$2.0 \quad$ Literature review}

After signing the Treaty of Nanjing with Britain in 1840, many Chinese cities were opened for foreign trade. With the advancement of western empires, the cities showed dramatic development, and China suffered serious economic unbalance. When the People's Republic of China was established in 1949, the population in the coastal regions reached $43 \%$ of the entire population, with $70.2 \%$ of the industrial gross production in the country concentrated in the regions. Since then, the widening of income disparity has become a major concern of the Chinese government as it is recognized as one of the results of China's dramatic economic growth and large labor mobility.

Table 1 shows the trend of levels of per capita income in the 3 highest income regions and lowest income regions in China, indicating that the ratio of income gap between the highest and lowest was doubled during the period of China's Planned Economy, which decreased under the reform and open-door policy until 1992, and then the disparity rose again. Also, the income gap among those highest 3 regions are reducing on a gradual basis, whereas the gap among the lowest 3 regions is widening. The regions with the highest and lowest per capita income in China are unchangingly Shanghai and Guizhou.

Whether the Chinese government's regional development policy narrows or widens regional disparity, it is an issue that many scholars and experts have dealt starting with the well-known debate by Lardy $(1976,1980)$ and Donnithorne $(1972,1976)$ in the 1970s. After that, many scholars and experts discusses this topic (Paine, 1981; Cannon, 1990; Lyons, 1991; Tsui, 1991, 1996; Kanbur and Zhang, 2005; Liu and Li, 2006; Fan et al, 2009; Gries and Redlin, 2009; Cai et al, 2010). 
Table 01: Change in the level of per capita income in the Provinces of China (Unit: yuan)

\begin{tabular}{|c|c|c|c|c|c|c|c|c|}
\hline & \multicolumn{2}{|l|}{1952} & \multicolumn{2}{|c|}{1978} & \multicolumn{2}{|c|}{1992} & \multicolumn{2}{|c|}{2009} \\
\hline \multirow{3}{*}{3 highest regions } & Shanghai & 430 & Shanghai & 2,498 & Shanghai & 8,652 & Shanghai & 78,326 \\
\hline & Tianjin & 299 & Beijing & 1,290 & Beijing & 6,804 & Beijing & 69,248 \\
\hline & Heilongjiang & 238 & Tianjin & 1,160 & Tianjin & 4,696 & Tianjin & 61,252 \\
\hline \multirow{3}{*}{3 lowest regions } & Sichuan & 69 & Yunnan & 226 & Anhui & 1,390 & Yunnan & 13,497 \\
\hline & Guangxi & 67 & Guangxi & 225 & Gansu & 1,384 & Gansu & 12,856 \\
\hline & Guizhou & 58 & Guizhou & 175 & Guizhou & 1,034 & Guizhou & 10,301 \\
\hline Ratio 1 & \multicolumn{2}{|l|}{4.98} & \multicolumn{2}{|c|}{7.90} & \multicolumn{2}{|c|}{5.29} & \multicolumn{2}{|c|}{5.70} \\
\hline Ratio 2 & \multicolumn{2}{|l|}{7.41} & \multicolumn{2}{|c|}{14.27} & \multicolumn{2}{|c|}{8.37} & \multicolumn{2}{|c|}{7.60} \\
\hline
\end{tabular}

Ratio1 indicates the mean proportion of the 3 highest income regions and 3 lowest income regions, and Ratio 2 refers to the proportion of the highest income regions and lowest income regions.

Sources: National Bureau of Statistics of China (2005) China Compendium of Statistics 1949-2004 (2010), China Statistical Yearbook,.

In addition, since the publication of statistic data of the population census conducted in 1982, indexes with regard to health, education, and human development, like infant mortality or illiteracy, have been widely utilized as variables (World Bank, 1984; Dreze and Sen, 1989; Bramall, 2001; Li and Zhu, 2006; Wang, 2006; Sicular et al, 2007; Keidel, 2009). Often-used other resources include Gross Value of Industrial and Agricultural Outputs (Riskin, 1987; Lee, 2000), Net Material Product and National Income Utilized (Lyons, 1991; Tsui, 1991). ${ }^{1}$

Even though people used the same analysis method, they often produced different research results, along with having reliably issues (Paine, 1981; Riskin, 1987; Tsui, 1996; Kanbur and Zhang, 1999; Im, 2005).

However, as a result of consistent efforts of the Chinese government to advance the clarity of the definition and statistics of variables, the reliability of statistic data has greatly improved (Zhao and Tong, 2000). In particular, the government's recently published statistic contains new indices that have not been aggregated before, providing possibility of conducting research in various aspects on regional inequality.

\subsection{Data, estimation indices and methodology}

\subsection{Data}

This study uses the statistics book "Compendium of Statistics 1949-2004" published by the Chinese government in 2005 (National Bureau of Statistics of China, 2005). The clear detailed information regarding GDP of each region from 1949 to 2004 is provided in this book. The data after 2004 is taken from "China Statistical yearbook."

Provinces, metropolitan cities, and autonomies in China were utilized as a basic unit for analysis, with the method of dividing regions into eastern, central, and western parts that the National Bureau of Statistics of China began to utilize in 2003.2 Hainan, which separated from Guangdong in 1988, is included in Guangdong because of data limitations. Four metropolitan cities including Beijing, Shanghai, Tianjin, and Chongqing were selected as research regions. Chongqing, in the meantime, although becoming autonomous from Sichuan province in 1997, has data aggregated separately since 1949, provided by the National Statistics Office, therefore is regarded as one of the metropolitan cities.

\subsection{Estimation indices and methodology}

Per capita GDP was converted to real GDP to estimate China's income inequalities by means of a GDP deflator, where estimation indices include Gini Coefficient and Coefficient of Variation to measure gaps between the spread of population and income distribution, and Theil Index that utilizes the concept of entropy. The coefficient formulae for these indices are as follows:

\subsubsection{Gini coefficient}

The formula to measure a Gini coefficient is shown below in equation (01):

\footnotetext{
${ }^{1}$ For detailed information on the resources previously used in the studies on spatial inequality, refer to <Table 1> of Gustafsson (2002).

2 Eastern region refers to 12 areas, including Beijing, Tianjin, Hebei, Liaoning, Shanghai, Jiangsu, Zhejiang, Fujian, Shandong, Guangdong, Guangxi and Hainan. Central region refers to 9 regions including Shanxi, Inner Mongolia, Jilin, Heilongjiang, Anhui, Jiangxi, Henan, Hubei and Hunan. Western region consists of 9 regions including Sichuan, Guizhou, Yunnan, Xizang, Shaanxi, Gansu, Qinghai, Ningxia and Xinjiang (Yang, 1990; Zhao and Gu, 1995; OECD, 2002: 694.
} 


$$
\text { Gini }=\left(\frac{1}{2 n^{2} u}\right) \sum_{i=1}^{n} \sum_{j=1}^{n}\left|y_{i}-y_{j}\right|
$$

Where, $u$ indicates national mean income in China, $y_{i}$ refers to the income of $i$ region (province), and $y_{j}$ represents the income of $j$ region (province). Also, $n$ refers to the number of the object regions and cities for measurement. The closer the estimated Gini coefficient is to 1 , the higher the degree of income inequality, and the income complains are determined as serious when the figure is over 0.4 .

\subsubsection{Coefficient of variation}

$$
\mathrm{CV}=\frac{\sqrt{\frac{1}{n} \sum_{i=1}^{n}\left(y_{i}-\bar{y}\right)^{2}}}{\bar{y}}
$$

The formula to measure a coefficient of variation is shown above in equation (02), where $Y_{i}$ refers to per capita income of $i$ region (province), $\bar{Y}$ is the national mean income of China. The higher the coefficient, the higher the inequality.

\subsubsection{Theil index}

$\mathrm{T}=\sum_{i=1}^{n} \frac{Y_{i}}{Y} \times \ln \left[\left(\frac{Y_{i}}{Y}\right) /\left(\frac{P_{i}}{P}\right)\right]$

The Theil index measured in general is shown in equation (03), where $Y_{i}$ represents the income of $i$ region (province), $Y$ refers to the gross income of China, $P_{i}$ indicates the population of $i$ region (province), and $P$ refers to the entire population of China. If the incomes among regions (provinces) are equally distributed, $\ln \left[\left(\frac{Y_{i}}{Y}\right) /\left(\frac{P_{i}}{P}\right)\right]$ on the right term comes $\ln 1$, with its value becoming 0 , and as a result the entire Theil index becomes 0 . The higher the degree of income complains among regions, the higher the coefficient of the Theil index. The Theil index is divided again into 2 terms, to measure the degree of inequality within inter-regions and intra-regions.

$$
\mathrm{T}=\mathrm{T}_{\text {inter }}+\mathrm{T}_{\text {intra }}
$$

Tinter refers to a Theil index to measure income disparity between the regions with its formula shown in the following equation (04)

$\mathrm{T}_{\text {inter }}=\sum_{g=1}^{G} Y_{g} \times \ln \left(\frac{Y_{g}}{P_{g}}\right)$

In equation (4), $Y_{g}$ indicates the component ratio (\%) of the income of the group $g\left(Y_{g}=\sum_{I \in S_{g}} Y_{i}\right)$, and $P_{g}$ represents the component ratio (\%) of the income of the group $g\left(P_{g}=\sum_{I \in S_{g}} P_{i}\right) .^{3}$

$$
\mathrm{T}_{\text {intra }}=\sum_{g=1}^{G} Y_{g} I_{g}
$$

\footnotetext{
3 The groups refer to the three regions including eastern, central and western China. Therefore, or represents the income or population proportion of those regions out of the entire country.
} 


$$
I_{g}=\sum_{I \in S_{g}}\left(\frac{Y_{i}}{Y_{g}}\right) \times \ln \left[\left(\frac{Y_{i}}{Y_{g}}\right) /\left(\frac{P_{i}}{P_{g}}\right)\right]
$$

$T_{\text {intra }}$ refers to the Theil index to measure income disparity within the regions, where $Y_{i}$ indicates the component ratio of income in region $i$, whereas $P_{i}$ represents the component ratio of population (\%) in Region $i$.

\subsection{Empirical results}

\subsection{Gini coefficient}

[Figure 1] shows inequality figures measured using the Gini coefficient. The Gini coefficient measured throughout the nation shows that the figures during the whole analysis period move between 0.3 and 0.35 in general, except for a few years. The coefficient tends to decrease from the second half of the 1970s, then increases in the 1990s. The eastern region of China fluctuates based on 0.4 until the second half of the 1970s, and then after the reform-opendoor policy, the inequality coefficient drops rapidly.

The Gini coefficients of the central and western regions of China move between 0.1 and 0.2 , which indicates that the provinces and cities in these two regions tend to gain lower than the average when it comes to income levels. The Gini coefficients of these two regions show slight drop, but not as much as the eastern region of China.

Figure 1: Inequality figures measured using the Gini Coefficient

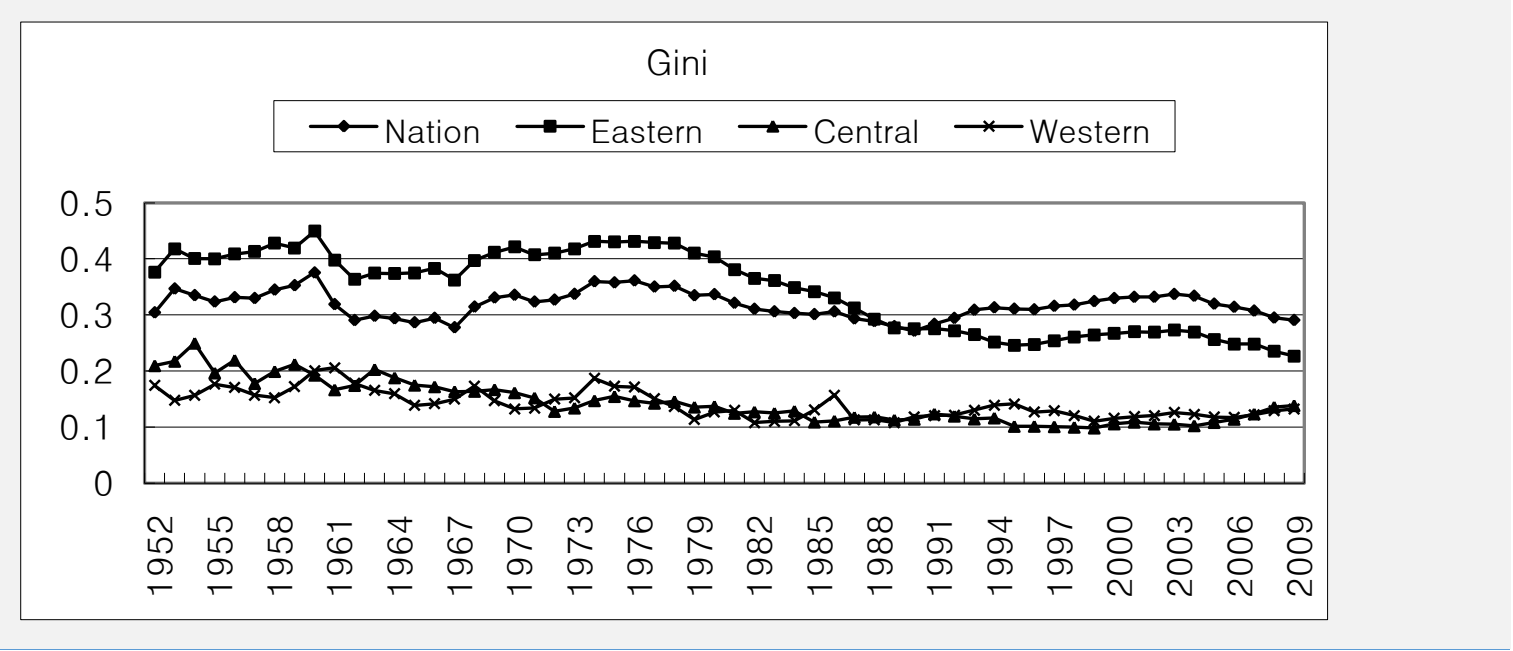

\subsection{Coefficient of variance (CV)}

Inequality figures measured using $\mathrm{CV}$ are shown in [Figure 2]. The $\mathrm{CV}$ of the whole nation plummets during the movement of the Great Leap Forward in the late 1950s. In the 1960s, the coefficient levels off, which then greatly increased from the start of the Cultural Revolution until the late 1970s. Entering the 1980s, the coefficient dips again, then increases in the 1990s, which on a whole is similar to the trend of the Gini coefficient, but higher in terms of the range of fluctuation. In the eastern region, the coefficient repeats its ups and downs until the 1970s, and then shows distinct decrease from the second half of the 1970s. Also, its coefficient shows a similar pattern to the pattern the country's CV, which then becomes lower than of the country's CV from the 1990s. The ranges of the fluctuations in the western and central regions of China show a leveling-off pattern with small fluctuation. 
Figure 2: Inequality figures measured using Coefficient of Variation

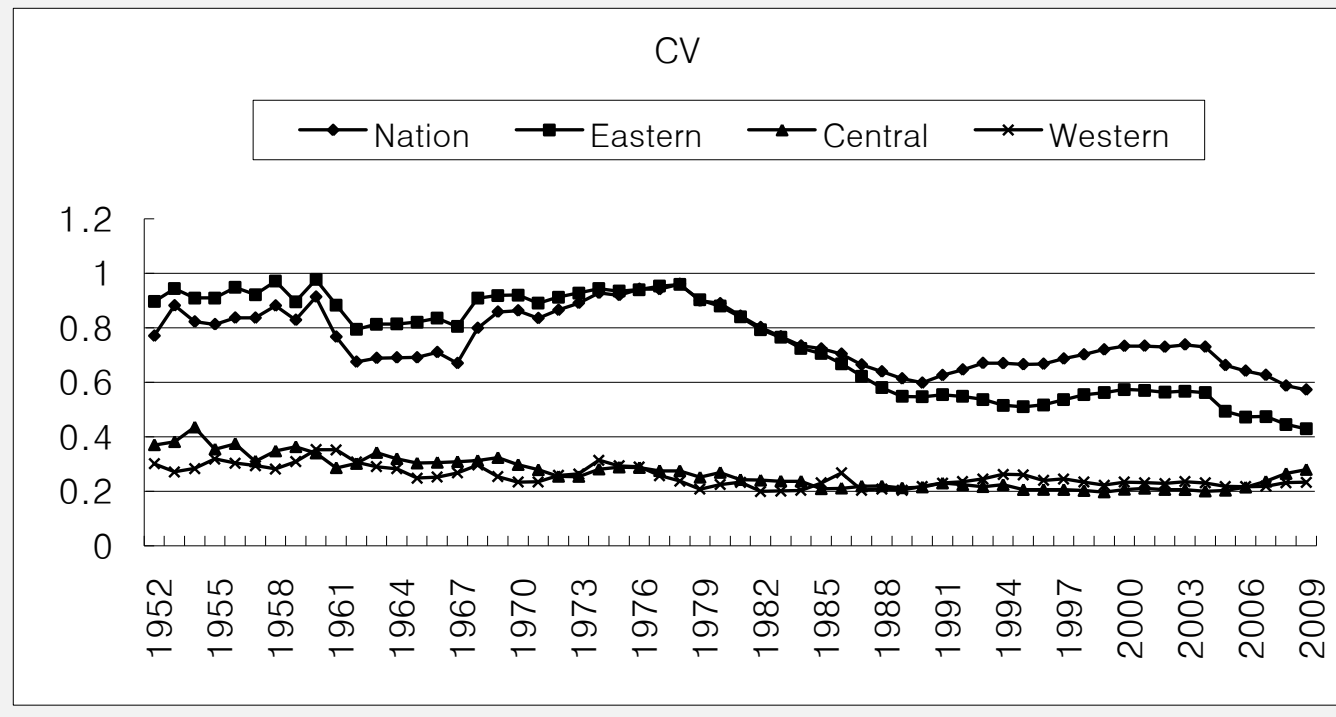

\subsection{Theil index}

[Figure 3] shows inequality figures measured using the Theil index. The Theil index is steadily decreases until the Cultural Revolution. Afterwards, when the Revolution starts, income equality rises again, and even exceeds the previous level, which continues to decrease from the late 1970s to the late 1990s. Entering the 1990s, the graph repeats the ups and downs, rising in the mid-1990s, and then declining again. These fluctuations of the Theil index of the whole nation move almost simultaneously with the change of Theil Intra. On the contrary, Theil Inter has a relatively insignificant to the whole nation's Theil index.

Figure 3: Inequality figures measured using Theil Index

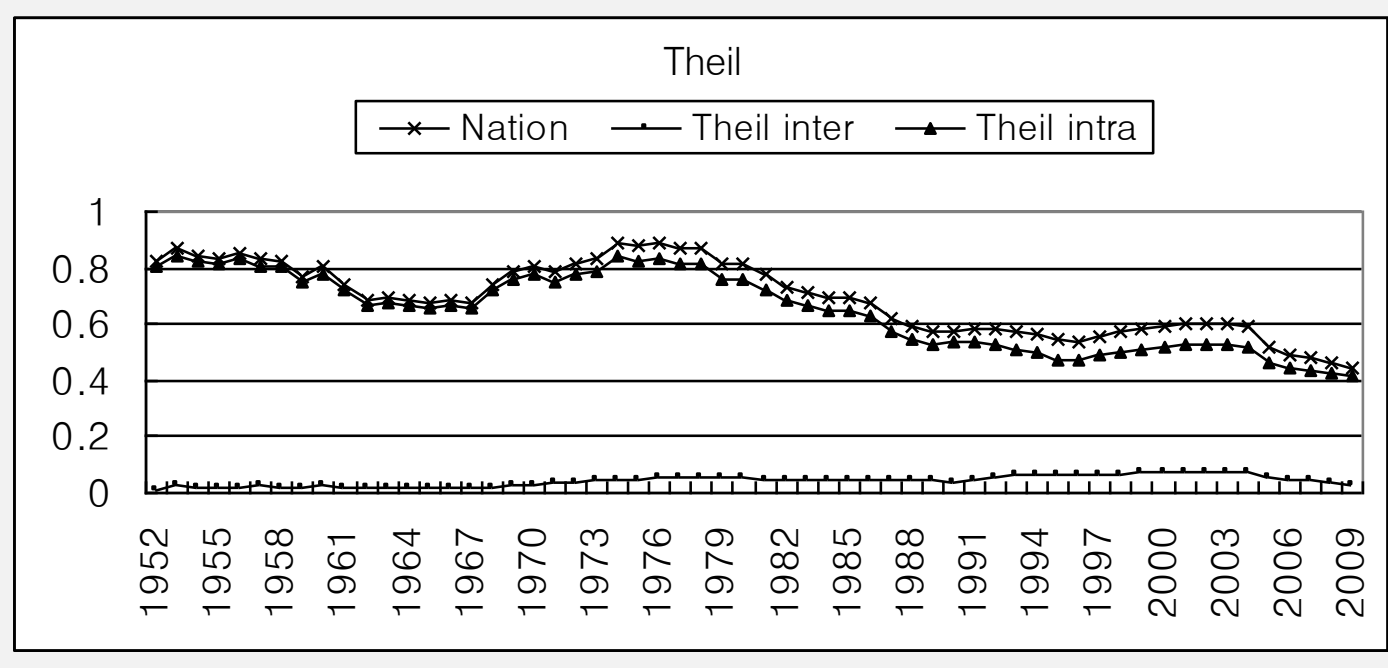

However, the indices of Theil Inter nearly sextupled compared to the figure in the first stage of the country establishment, when the reform and opendoor policy of the country allowed the eastern coastal regions to have rapid development, which in turn led to widening regional income disparity between the central and western inland regions. $(0.0129 / 0.0755)$

The causes of these fluctuations can be figured out in [Figure 4]. It shows that the income inequality in China is unexpectedly attributed mainly to an intra-regional factor rather than an inter-regional factor. In particular, the inequality coefficient within the eastern region of China can mostly represent the inequality index within the whole nation. In addition, with even development of the cities in the eastern coastal region in the wake of the reform and opendoor policy, the inequality in the eastern region showed dramatic decrease, which greatly contributed to reversing the whole nation's inequality index downwards. The regional income inequality in the western and central regions is decreasing, but not as significantly as the decrease in the eastern region. 
Figure 4: Inequality figures measured using Theil Intra Index

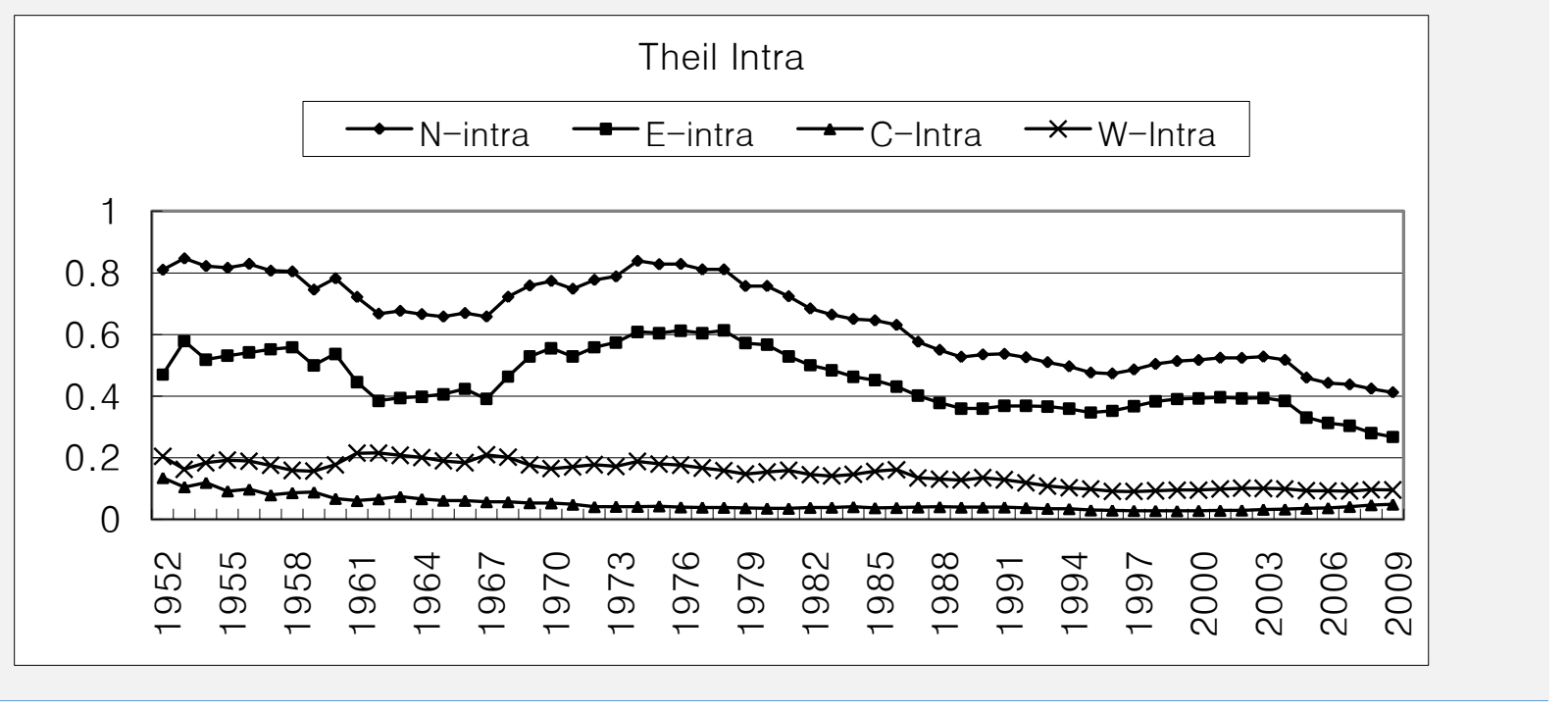

After taking those three predicted index results into consideration, the income inequality figures are up and down until the late 1970s, which then goes significantly downwards in the late 1980s when China put the reform and opendoor policy into practice. Then, in the 1990s, the coefficients show an upward trend.

The Gini coefficient, CV, and Theil index all clearly present that coefficients of the income inequality within the eastern region dipped rapidly after the end of the 1970s, which led to a decrease of income inequality coefficient in the whole nation. When the reform and opendoor policy was implemented, however, the eastern coastal region had rapid development, which has widened the income gap between the east coastal region and inlands.

\subsection{Effects regional development policies on income disparity}

In the previous section, the estimation of income inequality coefficients in China was taken into consideration in a broad manner. In this section, the change of income inequality coefficients will be considered more in detail by dividing into three periods, in line with the change of Chinese government's major policy direction for regional development. The first period is from 1949 when Mao Zedong established the People's Republic of China to 1977 shortly before the implementation of the reform and opendoor policy. The second period is from 1978 to 1991 during the first half of the reform and opendoor period, and the final period is from 1992 to 2010 when Deng Xiaoping reaffirmed the reform and opendoor policy by developing the socialist market economy.

\subsection{The first period: $1949-1977$}

The first period between 1949 and 1977 was the time when the central government after the establishment of the People's Republic of China started implementing the planned economy under the rule of Mao Zedong. When the Communists established the government, almost $70 \%$ of the industry was concentrated on the coastal regions, with 55\% of the coastal region products focused on Beijing, Tianjin, Shanghai, Shenyang, Anshan, Benxi, Dalian, Fushun. Consequently, the target of the First Planning initiated in 1953 was to relocate industries to inlands in order to fix this regional unbalance. The comprehensive goal was established to relocate industries mostly concentrated in coastal areas to the inland regions, and to make a balanced development. $80 \%$ of the 156 projects and $68 \%$ of the 694 industrial items were relocated in the central and western inland regions.

During the period of the second Five-year Planning that began in 1957, the Great Leap Forward Movement was rising as well. Great Leap Forward is an attempt to surpass Britain in the short-term period and ultimately catch up with the United States, by expanding social infrastructure, and cultivating croplands using rural labor. Accordingly, the government divided the country into 7 cooperation regions - Northeast, North, East, South, Central, Southwest, and Northwest - under the second planning, and individual regions were in operation with a view to develop an independent economic zone fully equipped with an industrial system to achieve self-reliance as fast as each could (Zhao and Gu, 1995: 392).

The indices for income inequality measured during this period show a record-high between 1959-1960, when the country was hit by devastating natural disasters, and then goes downward. This result is contrary to the 
opinion of some scholars who asserted that the regional income disparity became even wider, as the government controlled immigration between the urban and rural regions, and also resources were distributed in pursuit of industrialization, which in turn reduced the proportion of resources allocated to rural regions (Perkins and Yusuf, 1984; Kueh, 1989).

Mao made a development plan to relocate the country's major industries to its remote hinterland to protect them in the event of a third world war as the country was in bad terms with the Soviet Union and the United States. His idea was incorporated in the Third Planning (1966-1970) and Forth Planning (1971-1975) of the country. He envisaged three lines of defense on national territory, and all his endeavors were given to secure the third line of defense, the remote hinterland, called the Third Front. ${ }^{4}$ His strategy to build the industrial base in the Third Front, to secure its industries from foreign attacks, was put into practice, and industries of transportation, coal, electric power, steer, and nonferrous metals were constructed in mountains, dispersion, and in caves of the Third Front region. As a result, about 29,000 items were built in the region by the end of the 1970s, with about 2,000 large- mid scale companies and research complexes, 45 large-scale industrial bases, and 30 emerging cities (Park, 2006: 39).

Consequently, the investment in the eastern region out of the entire construction investments was reduced to $26.9 \%$ over the period of the Third Planning, while the portion of investment on the central and western regions located on the Third Front increased to no less than 52.7\%. Also, $60.5 \%$ of the national investments during the Forth Planning were concentrated on the inland regions (Yang, 1990: 236). Then, when the relationship between China and the United States improved from the mid-1970s, the strategy of the Third Front was weakened, and investment on coastal regions, such as developing oil fields in the eastern region, increased on a gradual basis as shown in Table 2 .

\begin{tabular}{lrrrr}
\hline & \multicolumn{5}{c}{ Table 2: State Investment in Fixed Assets (Unit: RMB 100 Million) } \\
\cline { 2 - 5 } Period & \multicolumn{2}{c}{ Coastal Region } & \multicolumn{2}{c}{ Interior Region } \\
\hline First Five-Year Plan & Amount & \% of Total & Amount & \% of Total \\
\hline Second Plan & 217.26 & 44.1 & 275.57 & 55.9 \\
\hline 1963-1965 & 462.62 & 40.6 & 675.61 & 59.4 \\
\hline Third Plan & 147.38 & 37.5 & 245.77 & 62.5 \\
\hline Fourth Plan & 262.85 & 29.4 & 631.21 & 70.6 \\
\hline Fifth Plan & 625.36 & 39.5 & 959.34 & 60.5 \\
\hline Including 1978 & 988.21 & 45.8 & $1,171.59$ & 54.2 \\
\hline \multicolumn{1}{c}{1979} & 200.83 & 44.0 & 255.35 & 56.0 \\
\hline \multicolumn{1}{c}{1980} & 221.09 & 45.7 & 262.95 & 54.3 \\
\hline 1953-80 Total & 248.69 & 47.2 & 278.46 & 52.8 \\
\hline \multicolumn{7}{r}{} & $2,703.68$ & 40.6 & $3,959.09$ & 59.4 \\
\hline
\end{tabular}

The inland-oriented balanced development policy executed during the central planning system after the foundation of China has caused many major industrial facilities to move from the eastern coast to inland regions, and many constructions took place through new large-scale investments. Such major industrial facilities, however, did not consider economic factors such as the economy of scale or external effects and moved into mountainous areas or remote areas, failing to establish industrial interrelationships with local industries at all, so it did not contribute much to the reduction of economic gaps with developed eastern regions. Rather, in the late 1970s, the relatively developed regions such as Shanghai, Liaoning, and Tianjin grew even faster, further expanding the income gap between regions.

The result can be identified by the increasing figures of the Gini Coefficient, CV, and Theil coefficient from [Figure 1] to [Figure 4], which is the opposite of the research results of Lardy (1980), Paine (1981) and Zhang et al (2001), who said that the income disparity was converged over the period, while it coincided with the research of Tsui (1991), Jian et al (1996) and Kanbur and Zhang (2005). They said the income disparity gap became wider during that period.

\subsection{The second period: 1978-1991}

In 1978 to 1991, China made a rapid economic growth by adopting the reform and opendoor policy and throwing the policy of seclusion that the country maintained all the while. Deng Xiaoping valued meritocracy

\footnotetext{
${ }^{4}$ Where, the first front refers to the southeast coastal region and soviet union border region, the second front the halfway between the 1st front and 3rd front based on Wuhan, Hubai in the middle Yangzi, and the third front represents the inland region far from the coast and the frontiers. The third front is divided into largely Sichuan, Guizhou, ShaanXi, Gansu, Qinghai, Ningxia, Yunnan, Hubai, Hunan, and Shansi provinces, or most narrowly into Sichuan, Guizhou, and ShaanXi..
} 
and competence based on utilitarianism and "The Getting Rich First theory," and took the opendoor policy to actively accept foreign systems, funding, technology, and talent instead of pursuing the self-reliance system. The policy-makers expanded foreign exchange for economic growth, absorbed advanced technologies from the west, and decided to attract foreign capital by selecting strategy zones to facilitate access to overseas markets and manage connection with overseas Chinese. To fulfill these policy strategies, Guangdong Province in 1979 was given trade autonomy in 1979, and four regions were designated as Special Economic Zones (SEZs), including Shenzhen, Zhuhai and Shantou in Guangdong and Xiamen in Fujian adjacent to Taiwan, Macao and HongKong. ${ }^{5}$

The local governments that have jurisdiction over the Special Economic Zones were given considerable discretion, such as having rights to export intermediate goods duty-free or holding foreign exchange to be earned, and attracting foreign capital by ensuring preferential treatment in several factors, including income tax, tariff, and exports and imports. At the same time, the government planned to construct the largest-scale Shanghai-Baishan Steering Factory Complex as a single project, and also 22 national core projects and new other projects were mostly allocated in Shanghai, Jiangsu, Zhejiang, Shandong, and Heilongjiang, to completely shift the direction of government development policy from the central and western regions all the while to the eastern region as priority.

In 1984, 14 more cities in the coastal region were open for foreign trade, with the suburbs of these 14 cities establishing Economic and Technical Development Zones and Industrial Development Zones, which received preferential treatment proportionate to the Special Economic Zones, at the same time. ${ }^{6}$ In 1985, the Pearl River Delta, the Min Nan region in Fujian, and the Yangtze River Delta were designated as Coastal Open Zones, whereas in 1988 and 1989 the whole regions of Liaoning Peninsula and Shandong Peninsula were additionally designated as Special Economic Zones to serve as crucial base regions for the Bohai Bay development strategy. Those zones that were opened for trade were given many preferential treatments, including government funding, foreign fund distribution, foreign exchange holding, tax, tariff, land use, foreign exchange, and investment.

This reform and opendoor policy allowed a great number of labor workers in rural areas to relocate to eastern regions or coastal regions, while the control of the central government on prices, inputs, and outputs reduced on a gradual basis. Also, more weight of production was placed on the private sector, while most foreign investments were concentrated on the eastern coastal region (Duan, 2008: 27). Government spending on the coastal regions went up, with $46.5 \%$ of the budget concentrated on the coastal regions in 1991, and the proportion of investment from social fixed assets went above $50 \%$.

On the other hand, these policy measures to develop eastern coastal regions with preferential treatments brought about concern that they could widen economic and income disparity between the central and western regions through the improvement of economic efficiency. Moreover, the trend of fiscal decentralization that began from the early 1980s led to considerable reduction in the power of the central government to redistribute national budget to low-income regions. Also, there was a following research result that as some rich east coastal provinces, such as Guangdong and Fujian, absorbed most of the foreign investment that flowed in China, financial capital entered into those prosperous regions, which in fact widened inter-regional income disparity between high-income and low-income regions. (Yang, 1990; Khan et al, 1992; Tusi, 1996; Wang, 2006).

However, this paper' analysis shows that all inequality indices during this period exhibited a distinct downward trend, therefore the previous claim regarding inter-regional income disparity seems unreasonable here. Another indication of converging income disparity is that the reduction of income inequality during this period was mostly attributed to reduction in income gap within the eastern region. Rapid growth of the eastern regions, particularly Zhejiang, Jiangsu, Guangdong, and Shandong, and the slowdown of growth in the former industrial cities in Liaoning, "Anti-mega city" policy against metropolitan cities, such as Beijing, Tianjin, and Shanghai, implemented in 1986 worked together to reduce income inequality drastically within the eastern region. Income inequality between the eastern region and inland regions did not increase considerably, which, in turn, reduced the total index of the national income inequality.

In other words, national income disparity was narrowed down along with the implementation of the reform and opendoor policy, mostly due to the reduction in income disparity among the eastern coastal regions (Lyons, 1991; Fan, 1995; Fujita and Hu, 2001; Lin and Liu, 2006; Gries and Redlin, 2009).

\footnotetext{
${ }^{5}$ Hai nan dao, a sub-special economic zone, was then designated as a special economic zone when it was raised to a province in April 1988.

6 The 14 coastal cities include Dalian, Qinhuangda, Tianjin, Yantai, Tsingtao, Lianyun, Nantong, Shanghai, Ningpo, Wenzhou, Fujian, Guangzhou, Zhanjiang, and Beihai.
} 


\subsection{The third period: $1992-2010$}

The final analysis period is from 1992 until 2010. Deng came to Guangdong and reiterated his will to expand the reform and opendoor policy through the socialist market economy, when the government's biased support for the eastern regions along with the reform and opendoor policy escalated conflicts between local and central governments.

As the government abolished the price planning and double price system under the Eighth Planning that began in 1991, the price system showed improvement, along with the considerably enhanced resource distribution function of the market. In addition, plans for developing the coasts and the Yangtze River Valley, or plans for developing the Yangtze River and Yellow River were included in the development plans, which was a new policy measure for the purpose of creating balanced regional development, called T-type or $\pi$-type development plans. Both plans commonly emphasize the connection of all inland regions with coastal regions, and also included development plans for provinces located in remote hinterlands. As a follow-up measure, in 1992, five cities along the Yangtze River, 15 inland provinces and autonomous regions were designated as open cities. The border cities adjacent to neighboring countries also opened the doors. ${ }^{7}$

Jiang Zemin, who took office following Den Xiaoping, continued the basic direction of Den Xiaoping for balanced regional development strategy, while he also had a special interest in the development of the central and western regions. Jiang reiterated in September of 1995, at the Five Plenum of Chinese Communist Party's $14^{\text {th }}$ Central Committee, that developing inland regions needed to be more valued and supported in the ninth planning, to reduce the trend of economic disparity.

In May 1996, at the meeting of the Ministry of Commerce of the People's Republic of China, he announced preferential policies to facilitate economic development in the central and western regions, urging the growth of the inland regions. ${ }^{8}$ Afterwards, in the early 2000s, Jiang declared general mobilization orders for the development of Western China before the entire Communist Party and all people, which enabled the development issue of the western region to become an official cabinet project of the $10^{\text {th }}$ National Planning that began in 2001 .

At the 16th Central Committee held in Nov 2002, leaders Jiang Zemin, Zhu Rongji, and Li Peng who led China's economic reform policy retired and new figures appeared, including Hu Jintao and Wen Jiabao. The specific development strategy of this new leadership was presented in September 2004 at the Four Plenum of Chinese Communist Party's 16 $6^{\text {th }}$ Central Committee, which was "construction of a harmonious society." This goal came from the reflection that China had caused three disparity issues (regional, urban-rural, and classes) based on China's growth fetishism and eastern region-centered development strategy.

Therefore, unlike the past preferential development strategy that Deng Xiaoping implemented, this government set a new national goal to create a society where all classes of life can share profits in harmony. ${ }^{9}$ To support this plan, the government continued to push forward the western development plan, and with the expansion of the network of national roads, China's Northeast Development Project through the reform of state-owned enterprises in Liaoning, Jilin, and Heilungjiang, implemented a development strategy for the central region. ${ }^{10}$ In addition, the Yangtze River Delta, Beijing and Tianjin, Chengdu and Chongqing, and three eastern provinces were designated as four core regions to be developed. It is important to note that the Chengdu economic zone was included for the first time in the four core regions.

Looking at the trend of income gap during the third period on Figure 4, all inequality indices turned upwards, which, however, declined under the implementation of the reform and opendoor policy, and then the income gap rose again. This coincides with Zheng and Chen's (2008) argument that compared to Deng's opening up polices, later development policies initiated by both Zhu Rongji government and Wen Jiabao government are less effective in terms of reducing regional inequality.

The cause of this fluctuation is the reverse of the trend of reduction in intra-regional income inequality with the fast growth of the eastern coastal regions. Another reason is that the income gap between the eastern region and

\footnotetext{
7 In August 1992, the Chinese government opened five cities including Chongqing, Yueyang, Wuhan, Zhouzhuang, and Wuhu, along with four frontiers (Harbin, Changchun, Hohhot, and Shijiazhuang) government facilities on the coastal provinces, and 11 inland government locations, including in Taiyuan, Hefei, Nanchang, Zhengzhou, Changsha, Chengdu, Guiyang, Xi'an, Lanzhou, Xining, and Yinchuan at the same time. 8 For more details on this, refer to Park (2006: 77).

9 This change of ideology was incorporated on the 11th five-year plan (2006 2010), indicating that the government's strategy was to convert from the 'Get rich first' policy to 'the theory of equal development.'

10 The central region consists of six provinces, including Hubei, Anhui, Henan, Shansi, Hunan, and Jiangxi.
} 
central-western regions became wider. In addition, income inequality, which has gradually declined all the while, began to increase little by little within the western regions, which indicates slight but additional impacts.

\subsection{Conclusion and policy implications}

This paper uses the statistics resources recently announced by the Chinese government to analyze the trend of regional imbalance since the foundation of the People's Republic of China to remove the issue of inconsistency and incoherency that the existing reports had. Through such analysis, we review the influence of the major regional development policies from the early days of foundation of China until now on the regional gaps in China.

The result of analysis showed some rather unforeseen facts when considering China's regional policy goals in the past. The first period is from the establishment of the People's Republic of China until the reform and opendoor policy. The result shows that income inequality coefficients are up and down. The second period is the age of the reform and opendoor policy. In this period, the income disparity in the eastern region drastically decreased, which in turn reduced the national income disparity among regions. The third period is from 1992 until 2010. Income disparity is again increasing from the early 1990s.

If this economic disparity among regions spreads more without control, it will cause more serious social and political problems, and will bring about negative impacts on China's political, economic, and social stability. China's Plan of Western Region Grand Development in the end of the 1990s or the recent plan for northeastern and central region development is also part of the measures to solve economic disparity among regions.

In order to attain the country's goal to reduce inter-regional income disparity, the government needs to consider support for underdeveloped regions in the eastern region of China within the minimum while it conducts preferential development plan for the central and western regions of China.

It desperately needs to attract investment for backward regions in the central and western areas and support them, by making the coordination function of the market economy and planned economy in harmony and integrating them in an organic manner.

One thing that needs to be noted is that coefficients of all estimated income inequality indexes have been decreasing since the mid 2000s. However, it may take more observation to decide whether such phenomenon is the result of the policy of 'building of a harmonious society' pursued by Hu Jintao.

\section{References}

Bramall, C. (2001). The quality of China's household income surveys. China Quarterly, 167, 689-705. http://dx.doi.org/10.1017/S0009443901000389

Cai, H., Chen Y., and Zhou L. (2010). Income and Consumption Inequality in Urban China: 1992-2003. Economic Development and Cultural Change, 58(3), 386-413.http://dx.doi.org/10.1086/650423

Cannon T. (1990). Regions: Spatial Inequality and regional Policy. The Geography of Contemporary China. London and NewYork: Routledge, 28-60.

Donnithorne, A. (1972). China's Cellular Economy: Some Economic Trends since the Cultural Revolution. China Quarterly, 52, 605-619. http://dx.doi.org/10.1017/S0305741000048116 . (1976). Centralization and Decentralization in China's Fiscal Management. China Quarterly, 66, 323-354.

Dreze, J. and Sen, A. (1989). Hunger and public Action. Oxford: Clarendon Press.

Duan, P. (2008). Influence of China's Population Flow in the Change of Reginal Disparity since 1978. China $\begin{array}{llll}\text { Population, } \quad \text { Resources } & \text { and }\end{array}$ http://dx.doi.org/10.1016/S1872-583X(09)60018-8

Fan, C. (1995). Of Belts and Ladders: State Policy and Uneven Regional Development in Post-Mao China. Annals of the Association of American Geographers, 85(3), 620-639. http://dx.doi.org/10.1111/j.1467-8306.1995.tb01807.x

Fan, S., Kanbur R., and Zhang X. (2009). Regional Inequality in China: Trends, explanations and policy response. New York: Routledge.

Friedman, E. (1987). Maoism and the Liberation of the Poor. World Politics, 39(4), 23-410. http://dx.doi.org/10.2307/2010226

Fujita, M. and Hu D. (2001). Regional disparity in China 1985-1994; the effects of globalization and economic liberalization. The Annals of Regional Science , 35(1), 37-3. http://dx.doi.org/10.1007/s001680000020 
Gries, T. and Redlin M. (2009). China's provincial disparities and the determinants of provincial inequality. Journal of Chinese Economic and Business Studies, 7, 259-281. http://dx.doi.org/10.1080/14765280902847783

Gustafsson, B. and Li S. (2002). Income inequality within and across counties in rural China 1988 and 1995. Journal of Development Economics, 69(1), 179-204. http://dx.doi.org/10.1016/S0304-3878(02)00058-5

Im, B. (2005). Revolution and Development of Chinese Economy. Seoul: Haenam.

Jian, T, Sachs, J. and Warner, A. (1996). Trends in Regional Inequality in China. China Economic Review, 7(1), 1-21. http://dx.doi.org/10.1016/S1043-951X(96)90017-6

Kanbur, R. and Zhang X. (1999). Which regional Inequality? The Evolution of Rural urban and inland-coastal inequality in China from 1983 to 1995. Journal of Comparative Economics, 27, 686-701. http://dx.doi.org/10.1006/jcec.1999.1612

Kanbur, R. and Zhang X. (2005). Fifty Years of Regional Inequality in China: a Journey Through Central Planning, Reform, and Openness. Review of Development Economics, 9(1), 87-106. http://dx.doi.org/10.1111/j.1467-9361.2005.00265.x

Keidel, A. (2009). Chinese Regional Inequalities in Income and Well-being. Review of Income and Wealth, 55, 538-561. http://dx.doi.org/10.1111/j.1475-4991.2009.00330.x

Khan, A., Griffin, C. Riskin, and Zhao W. (1992). Household income and its Distribution in China. China Quarterly, 132, 1029-1061. http://dx.doi.org/10.1017/S0305741000045525

Kueh, Y. (1989). The Maoist Legacy and China's New Industrialization Strategy. China Quarterly, 119, 420-447. http://dx.doi.org/10.1017/S030574100002289X

Lardy, N. (1976). Replies to Donnithorne. China Quarterly, 66, 340-354. http://dx.doi.org/10.1017/S0305741000033737

(1980). Regional growth and Income Distribution in China. Cambridge: Harvard University Press.

Lee, J. (2000). Changes in the source of China's regional inequality. China Economic Review, 11, 232-245. http://dx.doi.org/10.1016/S1043-951X(00)00019-5

Li, H. and Zhu Y. (2006). Income, Income inequality, and Health : Evidence from China. Journal of Comparative Economics, 34, 668-693. http://dx.doi.org/10.1016/j.jce.2006.08.005

Lin, Y. and Liu P. (2006). Development Strategies and Regional Income Disparities in China. World Institute for Development Economics Research,126.

Liu, T. and Li K. (2006). Disparities in factor contributions between coastal and inner provinces in post-reform China. China Economic Review, 17(4), 449-470. http://dx.doi.org/10.1016/j.chieco.2006.06.001

Lyons, T.(1991). Interprovincial disparities in China: Output and consumption, 1952-1987. Economic Development and Cultural Change,39,471-506. http://dx.doi.org/10.1086/451887

National Bureau of Statistics of China(2005). China Compendium of Statistics,1949-2004.

National Bureau of Statistics of China. China Statistical yearbook (each year).

OECD. (2002). China in the World Economy; the Domestic Policy Changes, Paris: rue André-Pascal.

Paine, S. (1981). Spatial Aspects of Chinese Developments-Issues, Outcomes and Politics, 1949-79. Journal of Development Studies,17(1), 95-132.

Park, J. (2006). China's new economic geography. Seoul: Donam Press.

Perkins, D. and Yusuf S. (1984). Rural Development in China, Baltimore: Johns Hopkins Univ. Press.

Riskin, C. (1987). China's Political Economy: The Quest for Development since 1949. Oxford: Oxford University Press.

Sicular, T., Yue X., Gustafsson B., and Li S. (2007). The Urban- Rural Income Gap and Inequality in China. Review of Income and Wealth, 53(1), 93-126. http://dx.doi.org/10.1111/j.1475-4991.2007.00219.x

Simoes, R. and Freitas, E. (2014). Urban attributes and regional differences in productivity: evidence the external economics of Brazilian micro-regions from 2000 - 2010. Journal of Economic \& Financial Studies, 2(1), 27-39. http://dx.doi.org/10.18533/jefs.v2i01.51

Theil, H. (1967). Economics and Information Theory. Amsterdam: North-Holland.

Tsui, K. (1991). China's regional inequality, 1952-1985. Journal of Comparative Economics, 15, 1-21. http://dx.doi.org/10.1016/0147-5967(91)90102-Y

(1996,). Economic reform and interprovincial inequalities in China. Journal of Development Economics, 50, 353-368. http://dx.doi.org/10.1016/S0304-3878(96)00406-3

Wang, X. (2006). Income Inequality in China and its Influencing Factors. World Institute for Development Economics Research, 126.

World Bank. (1984). China: the Health Sector. Washington D.C.

Yang, D. (1990). Patterns of China's regional development strategy. China Quarterly, 122, 230-257. http://dx.doi.org/10.1017/S0305741000008778

Zhang Z., Liu A., and Yao S. (2001). Convergence of China's Regional Incomes 1952-1997. China Economic Review, 12, 243-258. http://dx.doi.org/10.1016/S1043-951X (01)00053-0

Zhao, X. and Gu C. (1995). Policy Review on Spatial Strategy of Regional Development in China 1953-92. China Report, 31(3), 386-410. http://dx.doi.org/10.1177/000944559503100305 
Zhao, X. (1996). Spatial Disparities and Economic Development in China: 1953-92; A comparative study. Development and Change , 27(1), 131-163. http://dx.doi.org/10.1111/j.1467-7660.1996.tb00581.x

Zhao, X. and Tong S. (2000). Unequal Economic Development in China: Spatial Disparities and Regional Policy $\begin{array}{lllll}\text { Reconsideration, } & \text { 1985-1995. Segional } & \text { Studies, } & \text { 34(6), }\end{array}$ http://dx.doi.org/10.1080/00343400050085666

Zheng, Y. and Chen M. (2008). China's Regional Disparity and Its Policy Responses. China \& World Economy, 16(4), 16-32. http://dx.doi.org/10.1111/j.1749-124X.2008.00119.x 